\title{
Opportunistic screening for genital chlamydial infection. I: Acceptability of urine testing in primary and secondary healthcare settings
}

\author{
J M Pimenta, M Catchpole, P A Rogers, E Perkins, N Jackson, C Carlisle, S Randall, \\ J Hopwood, G Hewitt, G Underhill, H Mallinson, L McLean, T Gleave, J Tobin, \\ V Harindra, A Ghosh
}

Sex Transm Infect 2003;79:16-21

See end of article for authors' affiliations

Correspondence to: Dr Mike Catchpole, PHLS Communicable Disease Surveillance Centre, 61 Colindale Avenue, London NW9 5EQ, UK:

mcatchpole@phls.org.uk

Accepted for publication 4 October 2002

\begin{abstract}
Objectives: To determine the acceptability of opportunistic screening for Chlamydia trachomatis in young people in a range of healthcare settings.

Design: An opportunistic screening programme (1 September 1999 to 31 August 2000) using urine samples tested by ligase chain reaction (LCR). Data on uptake and testing were collected and in-depth interviews were used for programme evaluation.

Setting: General practice, family planning, genitourinary medicine clinics, adolescent sexual health clinics, termination of pregnancy clinics, and women's services in hospitals (antenatal, colposcopy, gynaecology and infertility clinics) in two health authorities (Wirral and Portsmouth and South East Hampshire).

Main participants: Sexually active women aged between 16 and 24 years attending healthcare settings for any reason.

Main outcome measures: Uptake data: proportion of women accepting a test by area, healthcare setting, and age; overall population coverage achieved in 1 year. Evaluation data: participants' attitudes and views towards opportunistic screening and urine testing.

Results: Acceptance of testing by women (16-24 years) was 76\% in Portsmouth and $84 \%$ in Wirral. Acceptance was lower in younger women (Portsmouth only) and varied by healthcare setting within each site. $50 \%$ of the target female population were screened in Portsmouth and $39 \%$ in Wirral. Both the opportunistic offer of screening and the method of screening were universally acceptable. Major factors influencing a decision to accept screening were the non-invasive nature of testing and treatment, desire to protect future fertility, and the experimental nature of the screening programme.

Conclusions: An opportunistic model of urine screening for chlamydial infection is a practical, universally acceptable method of screening.
\end{abstract}

G enital Chlamydia trachomatis infection is of particular public health concern because of recent rises in the reported number of cases $^{1}$ and the severe reproductive morbidity resulting from untreated infection and associated costs to the health service. It is the most common bacterial sexually transmitted infection (STI) in the United Kingdom and, as such, is the leading preventable cause of infertility. Although easily treatable with antibiotics, it is estimated that up to $70 \%$ of infections in women and $50 \%$ in men are asymptomatic; consequently, many people will be unaware of their infection and will not present for medical care. Current practice in the United Kingdom limits routine systematic screening for chlamydial infection to genitourinary medicine (GUM) clinics only. Screening programmes have been shown to be effective in Sweden ${ }^{2}$ and the United States. ${ }^{3}$ However, as it was uncertain whether the methodologies employed would be suitable for a UK based programme, the Department of Health (England) commissioned this study after considering expert advice from the chief medical officer's expert advisory group on Chlamydia trachomatis ${ }^{4}$ and the national screening committee.

While the use of non-invasive testing methodologies is likely to increase the acceptability of testing to the general population, it was unclear, before this pilot programme, whether this would hold true if screening were offered opportunistically in a variety of settings. This study aimed to evaluate whether an opportunistic screening programme in England would be acceptable to the target population. In this paper, we focus on the uptake and acceptability of opportun- istic screening and the views of young people participating in the programme.

\section{METHODS}

Full details of the study methodology have been previously reported. ${ }^{5}$ The pilot was undertaken in two health authorities (HA) in England (Wirral and Portsmouth and South East Hampshire, as in existence before April 2002), between 1 September 1999 and 31 August 2000. The main target group was sexually active women aged between 16 and 24 years of age attending a range of healthcare settings. In addition, the following groups were also offered screening:

- Women of any age attending for termination of pregnancy or instrumentation of the uterus (Wirral only)

- Men (aged 16-24 years) attending GUM clinics or youth sexual health clinics

- Women (or men at the above settings) aged under 16 years if attending for a sexual health reason or considered to be able to make an informed decision, as established by the House of Lords ruling in the Gillick case.

Participants were given an information booklet on chlamydial infection including details of the programme and a standardised test request form to record whether or not they wished to be screened and then demographic details (name, age, sex, ethnicity, address). Those consenting to screening also provided information on the presence of symptoms, the 
Table 1 Number of participating health sites and health service utilisation by sexually active women (16-24 years) during chlamydia pilot programme

\begin{tabular}{|c|c|c|c|c|}
\hline \multirow[b]{2}{*}{ Healthcare setting } & \multicolumn{2}{|l|}{ Portsmouth } & \multicolumn{2}{|l|}{ Wirral } \\
\hline & $\begin{array}{l}\text { Number of clinics } \\
\text { or practices }\end{array}$ & $\begin{array}{l}\text { Eligible women attending } \\
\text { healthcare setting } \\
\text { (n, \% estimated population*) }\end{array}$ & $\begin{array}{l}\text { Number of clinics } \\
\text { or practices }\end{array}$ & $\begin{array}{l}\text { Eligible women attending } \\
\text { healthcare setting } \\
\text { (n, \% estimated populationt) }\end{array}$ \\
\hline General practice $\ddagger$ (GP) & 77 & 16577 (69.1) & 61 & $10715(83.1)$ \\
\hline Family planning clinics (FPC) & 10 & $8756(36.5)$ & 12 & $1695(13.1)$ \\
\hline Adolescent sexual health clinics (youth) & 5 & $454(1.9)$ & 2 & $3790(29.4)$ \\
\hline GUM clinics (GUM) & 1 & 3080 (12.8) & 1 & NA \\
\hline Antenatal clinics (ANC) & 4 & $1323(5.5)$ & 1 & $1265(9.8)$ \\
\hline Gynaecology clinics (GYN) & 4 & NA & 2 & $437(3.4)$ \\
\hline Colposcopy clinics (COL) & 2 & $432(1.8)$ & 2 & NA \\
\hline Termination of pregnancy clinics (TOP) & 1 & $826(3.4)$ & 2 & 502 (3.9) \\
\hline Infertility clinic (INF) & 1 & NA & 1 & $37(0.3)$ \\
\hline Chlamydia pilot office (CPO) & 1 & NA & 1 & NA \\
\hline Total screening sites & 106 & & 85 & \\
\hline
\end{tabular}

*Estimated population of sexually active women aged 16-24 years in Portsmouth $=24000$

tEstimated population of sexually active women aged 16-24 years in Wirral $=12900$

Includes 9 satellite clinics and 3 naval based practices in Portsmouth.

$\mathrm{NA}$ = data were not available.

method by which they would receive their results (letter to their home or alternative address or by phone) and 15-20 ml of urine in a sterile, plastic container. Health professionals completed information on the main reason for patient attendance and test on a tear-off slip at the end of the form. In order to protect patient confidentiality, the list of reasons was removed from the form leaving only a coded list after completion. Samples were delivered to participating laboratories or refrigerated at $2^{\circ} \mathrm{C}$ to $8^{\circ} \mathrm{C}$ for a maximum of 4 days if transport was not immediately available. Samples were tested by the ligase chain reaction (LCR) according to manufacturer's instructions (Abbott LCx Chlamydia trachomatis assay, Abbott Laboratories Diagnostic Division, IL, USA). Test results were sent from the laboratory to the test initiator (for their information only) and to project research nurses (PRNs), based at a coordinating office for each health authority. The PRNs informed all participants of their results using the method given by the participant on their test form, and provided advice for both participants and health professionals. Participants testing either positive or equivocal were invited to contact the PRNs to discuss their subsequent management. In the Wirral, the PRNs were trained community health advisers and also acted in this capacity.

Participating healthcare settings are shown in table 1 . In total, 83\% (65/79) of general practices (GPs) in Portsmouth and $91 \%(61 / 67)$ in Wirral participated in the programme. In Portsmouth, the majority of GPs starting screening within the first month of the programme, as did the non-GP sites in both HAs. In Wirral, GPs were gradually phased in to the programme over 6 months.

To compensate for programme specific workload, clinics were financially remunerated, the level of which was determined by local and service agreements. In the Wirral, all sites received a capitation payment ( 3 ) based on the estimated number of women in the target age group attending each clinic, and then an additional 10 per test undertaken. In Portsmouth, no capitation payments were made; the first 6000 tests undertaken were paid at $£ 25$ and then $£ 10$ thereafter. Costs for supplies and treatment were centrally funded. The study received ethical approval from both local and PHLS research ethics committees.

\section{QUANTITATIVE DATA MANAGEMENT AND ANALYSIS}

To allow patient based analyses, episodes belonging to the same participant were matched based on their identifying details. Episodes with the same NHS number, obtained from the local family health service authorities (FHSAs), were considered to be the same person and were automatically assigned a unique patient identifying (PI) number. For all other episodes, an iterative process, involving the generation of reports that identified episodes falling into various categories depending on the amount of identifying information, was used for matching and PIs were assigned manually. Finally, all episodes that had not been matched to any other were given unique PIs.

The size of the eligible population (women 16-24 years) was determined using mid-1999 population estimates from the Office for National Statistics. ${ }^{6}$ Estimates of the proportion of women in this age group who were sexually active were calculated using data from the second National Survey of Sexual Attitudes and Lifestyles (NATSAL 2000). ${ }^{7}$ Each participating clinic/practice provided information on the number of women in the target age group who had attended during the 1 year period. Data were analysed using descriptive statistics and logistic regression in STATA 7.0. ${ }^{8}$ Results focus on the main target group of women (16-24 years); results of testing in the additional groups (women aged under 16, those aged over 24 attending for termination of pregnancy, and men) will not be included in this paper. Data were analysed separately for each HA and no formal comparisons between HAs were made because geographic differences were confounded with the differences in study methodology (recruitment of GPs to the study) and differential service provision.

\section{QUALITATIVE DATA COLLECTION AND ANALYSIS}

An independent evaluation of the programme explored participants' views on the acceptability of opportunistic screening using self completion questionnaires and in-depth interviews. In general, the findings from the two types of data collected were complementary and so to summarise, we concentrate on detailed results from the qualitative work only in this paper and results from the self completion survey will be reported elsewhere. A multistage approach was adopted for recruitment; self completion questionnaires were distributed to a random sample of participating screening sites and staff from each site gave out the questionnaires to individuals being screened. Attached to, but separate from, the self completion questionnaire was an information sheet inviting people to participate in the qualitative study and to provide their name and contact details. Almost 400 questionnaires were received and although 80 young people provided contact details, only 25 people (24 women and one man) were available for interview. The reasons for this low response are multiple, most 
Table 2 Description of eligible women offered screening during the chlamydia pilot programme

\begin{tabular}{|c|c|c|}
\hline & Portsmouth & Wirral \\
\hline \multicolumn{3}{|l|}{ Characteristic } \\
\hline $\begin{array}{l}\text { Total number of eligible } \\
\text { participants* }\end{array}$ & 16145 & 6541 \\
\hline $\begin{array}{l}\text { Total number of screening episodes } \\
\text { from eligible participants (tests } \\
\text { accepted or refused) }\end{array}$ & 25954 & 8733 \\
\hline \multicolumn{3}{|l|}{ Age† (\% eligible patients) } \\
\hline$<16$ years & $358(2.2)$ & $316(4.8)$ \\
\hline $16-19$ years & $7110(44.0)$ & $2642(40.4)$ \\
\hline $20-24$ years & 8671 (53.7) & $3219(49.2)$ \\
\hline $25-30$ years & 0 & $134(2.0)$ \\
\hline$>30$ years & 0 & $194(3.0)$ \\
\hline \multicolumn{3}{|l|}{ Ethnicity (\% known ethnicity) } \\
\hline White & $14310(97.3)$ & $5242(98.6)$ \\
\hline Other $\ddagger$ & 391 (2.7) & $73(1.4)$ \\
\hline Unknown (\% total eligible) & $1444(8.9)$ & $1226(18.7)$ \\
\hline \multicolumn{3}{|c|}{$\begin{array}{l}\text { *Tabulated data excludes } 6 \text { participants from Portsmouth and } 13 \\
\text { from Wirral where sex is unknown. } \\
\text { †Age breakdown excludes a further } 8 \text { participants from Portsmouth } \\
\text { and } 36 \text { from Wirral where age is unknown. } \\
\text { †Because of small sample sizes, all non-white ethnic groups have } \\
\text { been combined. }\end{array}$} \\
\hline
\end{tabular}

commonly being insufficient or out of date contact details (particularly mobile phone numbers) and also participants changing their minds at a later date. Interviews took place in a venue of the respondent's choosing and were tape recorded then transcribed verbatim. The open coding method of content analysis ${ }^{9}$ was used to identify themes that related to the main study aims.

\section{RESULTS}

\section{Screening and uptake dato}

Target and study population

Using ONS and NATSAL 2000 data, it was estimated that there were 24000 sexually active women in the target age group
(16-24 years) in Portsmouth and 12900 in Wirral. Table 1 illustrates healthcare setting utilisation of these women during the study. In both sites, the highest attendance rates were in general practice; almost $70 \%$ of the eligible population attended once or more within the year in Portsmouth and 83\% in Wirral. Family planning clinics (FPCs) and youth services were also relatively well utilised; in Wirral, $29 \%$ attended the Brook clinic (the main youth clinic) and 13\% attended FPCs; however, in Portsmouth, 37\% attended FPCs but only a small proportion utilised the youth clinics $(2 \%)$.

The number of people offered the test

The total number of eligible female participants offered screening was 16145 in Portsmouth and 6541 in Wirral, generating a total of 25954 screening episodes (tests accepted and declined) in Portsmouth and 8733 in Wirral (see table 2). In addition, a small proportion of women who were offered testing were not sexually active so were ineligible for inclusion in the study; $718(4 \%)$ in Portsmouth and $134(2 \%)$ in Wirral. In both health authorities, over $97 \%$ of the attending population were of white ethnicity.

\section{Test acceptance}

In Portsmouth, 66\% (15 781/24 000) of the eligible female population (16-24 years) were offered screening, of whom $76 \%$ ( 11 999/15 781) accepted testing. The programme therefore achieved $50 \%$ population coverage in 1 year. In Wirral, $45 \%(5861 / 12900)$ of the female population were offered screening with $84 \%(4931 / 5861)$ accepting a test; $39 \%$ population coverage. The slightly lower population coverage achieved in Wirral was probably due to the phased implementation of general practices into the screening programme.

Overall acceptance of testing by the target age group in females was significantly higher in Wirral than in Portsmouth $(\mathrm{p}<0.001)$. In Wirral, there was no significant variation in acceptance rates in women by single year of age, observed rates were however slightly lower in under 16 year olds and 16 year olds (both $80 \%$ ). In Portsmouth, acceptability increased significantly with age $(p<0.001)$ and was lower in those aged

Table 3 Acceptance rates of screening in women (16-24 years) at different healthcare settings during the chlamydia pilot programme

\begin{tabular}{|c|c|c|c|c|}
\hline \multicolumn{5}{|l|}{ Portsmouth } \\
\hline $\begin{array}{l}\text { Healthcare } \\
\text { setting }\end{array}$ & $\begin{array}{l}\text { Offered } \\
\text { screening (n) }\end{array}$ & $\begin{array}{l}\text { Accepted } \\
\text { screening (n) }\end{array}$ & $\begin{array}{l}\text { Acceptance of } \\
\text { screening }(\%, 95 \% \mathrm{Cl})\end{array}$ & $\begin{array}{l}\text { Attending but screened } \\
\text { elsewhere ( } n, \% \text { total offered) }\end{array}$ \\
\hline GP & 10062 & 7546 & 75.0 (74.1 to 75.8$)$ & $394(3.9 \%)$ \\
\hline FP & 5665 & 3057 & 54.0 (52.7 to 55.3$)$ & $928(16.4 \%)$ \\
\hline GUM & 1253 & 1215 & 97.0 (95.9 to 97.8$)$ & $8(0.6 \%)$ \\
\hline Youth & 241 & 150 & $62.2(55.8$ to 68.4$)$ & $27(11.2 \%)$ \\
\hline ANC & 201 & 165 & 82.1 (76.1 to 87.1 ) & $6(3.0 \%)$ \\
\hline $\mathrm{COL}$ & 48 & 36 & $75.0(60.4$ to 86.4$)$ & $1(2.1 \%)$ \\
\hline GYN & 45 & 41 & 91.1 (78.8 to 97.5$)$ & $1(2.2 \%)$ \\
\hline TOP & 646 & 358 & 55.4 (51.5 to 59.3$)$ & $196(30.3 \%)$ \\
\hline INF & 5 & 3 & 60.0 (14.7 to 94.7$)$ & $0(0)$ \\
\hline Total & 15781 & 11999 & 76.0 (75.4 to 76.7$)$ & \\
\hline \multicolumn{5}{|l|}{ Wirral } \\
\hline $\begin{array}{l}\text { Healthcare } \\
\text { setting }\end{array}$ & $\begin{array}{l}\text { Offered } \\
\text { screening (n) }\end{array}$ & $\begin{array}{l}\text { Accepted } \\
\text { screening (n) }\end{array}$ & $\begin{array}{l}\text { Acceptance of } \\
\text { screening }(\%, 95 \% \mathrm{Cl})\end{array}$ & $\begin{array}{l}\text { Attending but screened } \\
\text { elsewhere ( } n, \% \text { total offered) }\end{array}$ \\
\hline GP & 1940 & 1579 & 81.4 (79.6 to 83.1$)$ & $93(4.8 \%)$ \\
\hline FP & 1463 & 999 & $68.3(65.8$ to 70.7$)$ & $154(10.5 \%)$ \\
\hline GUM & 617 & 569 & 92.2 (89.8 to 94.2$)$ & 35 (5.7\%) \\
\hline Youth* & 1253 & 1028 & 82.0 (79.8 to 84.1$)$ & $47(3.8 \%)$ \\
\hline ANC & 483 & 434 & 89.9 (86.8 to 92.4$)$ & $19(3.9 \%)$ \\
\hline COLP & 251 & 217 & 86.5 (81.6 to 90.4$)$ & 15 (6.0\%) \\
\hline GYN & 34 & 29 & 85.3 (68.9 to 95.0$)$ & $2(5.9 \%)$ \\
\hline TOP & 157 & 60 & 38.2 (30.6 to 46.3$)$ & $59(37.6 \%)$ \\
\hline INF & 8 & 8 & $100.0(63.1$ to 100.0$)$ & $0(0)$ \\
\hline Total & 5861 & 4931 & 84.1 (83.2 to 85.1$)$ & \\
\hline
\end{tabular}


Table 4 Effective screening rate (ESR) in women (16-24 years) achieved at different healthcare settings during the chlamydia pilot programme

\begin{tabular}{|c|c|c|}
\hline \multirow{2}{*}{$\begin{array}{l}\text { Healthcare } \\
\text { setting }\end{array}$} & \multicolumn{2}{|c|}{ Effective screening rate $(\%, 95 \% \mathrm{Cl})$} \\
\hline & Portsmouth & Wirral \\
\hline GP & 45.5 (44.8 to 46.3$)$ & $14.7(14.1$ to 15.4$)$ \\
\hline FP & 34.9 (33.9 to 35.9$)$ & 58.9 (56.6 to 61.3) \\
\hline GUM & 39.4 (37.7 to 41.2$)$ & NA \\
\hline Youth & $33.0(28.7$ to 37.6$)$ & 27.1 (25.7 to 28.6$)$ \\
\hline ANC & $12.5(10.7$ to 14.4$)$ & 34.3 (31.7 to 37.0 ) \\
\hline $\mathrm{COL}$ & $8.3(5.9$ to 11.4$)$ & NA \\
\hline GYN & NA & 6.6 (4.5 to 9.4$)$ \\
\hline TOP & 43.3 (39.9 to 48.8 ) & $12.0(9.2$ to 15.1$)$ \\
\hline INF & NA & $21.6(9.8$ to 38.2$)$ \\
\hline
\end{tabular}

$\mathrm{NA}=$ denominator data not available (see table 1).

between 16-19 years (74\%) compared to 20-24 year old women $(77 \%)$.

Within each health authority, acceptance rates for women in the target age group varied considerably between healthcare settings (see table 3 ) and were over $50 \%$ in the majority of settings. In both areas, rates were highest in GUM clinics (97\% and $92 \%$ in Portsmouth and Wirral respectively) and lowest in FPC (54\% and $68 \%$ ) and TOP clinics (55\% and 38\%). However, as over $25 \%$ of participants in Wirral and $34 \%$ in Portsmouth were offered tests on more than one occasion, the variation in test acceptance is likely to be influenced by whether participants had previously accepted screening in other settings. The final column in table 3 indicates the number of participants who attended and did not accept screening in a specified healthcare setting but were screened elsewhere. In both areas, the healthcare settings where acceptance rates were lowest (FPC and TOP) had the highest proportions of participants who were known to have been screened in other settings; over $30 \%$ of TOP attenders and over $10 \%$ of FPC attenders were screened elsewhere during the study. The effective screening rate (ESR) is illustrated in table 4; this is the proportion of the total attending population actually tested. Health professionals participating in the programme indicated that screening was not offered to all eligible patients at every episode of attendance because of high staff workload and time constraints; consequently, ESR is much lower than the acceptability rates seen. The ESR was highest in general practice in Portsmouth (46\%) and in FPCs in Wirral (59\%).

Table 5 indicates the main reasons for attendance for women in the target group who accepted screening. In both sites, contraception was the main reason for attendance in the majority of episodes (39\% in both sites) and the screening programme itself was the main reason for attendance in $6 \%$ of episodes in Portsmouth and 16\% in Wirral. Although genital tract symptoms were stated as the main reason for attendance in $7 \%$ of accepted episodes in Portsmouth, the presence of symptoms was recorded on the test forms in 34\% of accepted episodes. Similar proportions were seen in Wirral $(8 \%$ main reason for attendance, $39 \%$ reported symptoms). After adjusting for age and healthcare setting of attendance using logistic regression and analysing first tests only, women who were asymptomatic were significantly less likely to accept screening than those who reported symptoms (OR $=0.33$ and 0.04 in Portsmouth and Wirral respectively).

Tests declined

In Portsmouth, 24\% (3782/15 781) of 16-24 year old women offered screening declined all offers of testing during the programme; however, $20 \%$ of these women indicated that they had been previously tested for infection. Decliners were slightly younger (mean age 19.7 years) than those who accepted (mean age 20.0 years, $\mathrm{p}<0.001$ ). A similar pattern was seen in Wirral where $16 \%(930 / 5861)$ of women aged 16-24 years declined testing, $22 \%$ of whom had been already tested. Decliners were again slightly younger than those accepting testing (mean age 19.8 years and 20.0 years respectively; $\mathrm{p}=0.03$ ).

\section{Evaluation data}

Acceptability of opportunistic screening

In general, women were pleased to be asked to take part in the programme and the majority had not been screened before. An individual's initial response to screening varied with location and the length of time the programme had been running. A minority of interviewees screened early in the programme, before high awareness levels were generated, reported they needed reassurance that they were not being singled out as being "sexually active" or "at risk" of having chlamydia. In the beginning, respondents attending sexually related services (including FPCs) were the most comfortable with the offer of screening for chlamydia (see quote 1 in box).

\section{Motivation for accepting the offer of screening}

The opportunistic nature of the test was recognised as being important given that the infection could be asymptomatic. In the absence of symptoms, many respondents reported that they would not have been sufficiently motivated to seek out screening themselves (quote 2). A combination of factors encouraged these young women to accept screening. Both formal (that is, health professionals, pilot leaflet, publicity campaigns) and informal (for example, family or friends)

Table 5 Reason for attendance of women (16-24 years) accepting screening at healthcare settings during the chlamydia pilot programme

\begin{tabular}{lcr}
\hline Reason for attendance* $^{*}$ & Portsmouth (n, \%) $\dagger$ & Wirral (n, \%) $\dagger$ \\
\hline Contraception & $4499(38.8)$ & $1839(39.2)$ \\
Other reason (not related to genital tract) & $3171(27.4)$ & $472(10.1)$ \\
Screening programme & $783(6.8)$ & $872(18.6)$ \\
Genital tract symptoms & $857(7.4)$ & $396(8.4)$ \\
Antenatal & $387(3.3)$ & $342(7.3)$ \\
Termination of pregnancy & $351(3.0)$ & $179(3.8)$ \\
Cervical smear & $310(2.7)$ & $253(5.4)$ \\
GUM STI screening & $521(4.5)$ & $72(1.5)$ \\
Previous unsatisfactory test & $592(5.1)$ & $33(0.7)$ \\
Fertility & $86(0.7)$ & $34(0.7)$ \\
Colposcopy & $26(0.2)$ & $189(4.0)$ \\
Referral of positive (Wirral only) & $0(0)$ & $9(0.2)$ \\
Unknown (\% total episodes) & $1523(13.2)$ & $5460(16.4)$ \\
\hline
\end{tabular}

* Reason for attendance of episodes where test accepted (excluding those undertaken for test of cure). $\dagger \%$ of total where reason is known (11 583 in Portsmouth and 4690 in Wirral). 
What the participants said: Original quotes from women interviewed

Acceptability of opportunistic screening

Quote 1: "Honestly, in the Brook it didn't bother me. There are so many people going in for things like pregnancy tests, they wouldn't bat an eyelid. If you walk through the room with a sample in your hand no one bats an eyelid. So, I took the bottle, put it in my pocket, went down to the toilet, filled it and then put it back in my pocket and gave it to them." Female, Brook Clinic, Wirral (negative)

Motivation for accepting screening

Quote 2: "Yeah, I'm sure if I hadn't gone to get my pills - or if I'd gone six months later - the leaflets may not have been handed out then and I still wouldn't know lof positive result)." Female, FPC, Portsmouth (positive)

Quote 3: "If you did have chlamydia there is not always noticeable symptoms and it is like a silent disease and it can make you infertile without you knowing." Female, GUM and youth, Portsmouth (negative)

Quote 4: "I just took the test out of curiosity. It was OK so I didn't really need one. But I just knew it was something that could be there for a while and like I say you know, it could affect your fertility if you were, you know, to decide to have a pregnancy later on." Female, Brook Clinic, Wirral (negative)

Acceptability of being asked to give a urine sample Quote 5: "If you can test it by urine, then test it by urine, because it's far less embarrassing. No one feels comfortable doing swabs and I think a lot of people would have said no and I think I probably would have done." Female, FPC, Portsmouth (negative)

Quote 6: "I just think, with sexual health, at the end of the day, receptionists are there to book appointments, aren't they? Not to ask if you want a sexual disease test." Female, GP, Portsmouth (negative)

sources played a part in raising the profile of the infection. The most important factors influencing a person's decision to accept screening were being potentially at risk of infection, possible long term impact on fertility, and that chlamydia was easily treated (quotes 3 and 4).

\section{Acceptability of being asked to give a urine sample}

All the women interviewed found giving a urine sample acceptable, including women who had little or no experience of sexual health services. Almost all considered it quick and easy to undertake and the simplicity of the test enabled people to accept testing and encourage their friends to be screened. The majority of respondents said they would not have accepted screening if it had entailed having a swab (quote 5).

Although the test was universally acceptable, there was some dissatisfaction expressed in the way screening was offered, mainly from women attending general practice. The screening model required receptionists to hand out chlamydia information leaflets to patients on arrival and some respondents felt that this compromised their confidentiality because of lack of privacy. A minority of people considered that specimen handling could have been managed more discreetly to avoid the receptionists collecting in specimens (quote 6).

\section{CONCLUSIONS}

In England, this is the first large scale trial of opportunistic screening for genital chlamydial infection undertaken in a wide range of healthcare settings, where women were asked to participate regardless of their original reason for consultation. It was important that testing should reach those who were asymptomatic and those who would not normally consider themselves at risk of infection. The high response rate and significant population coverage achieved indicates that an opportunistic approach is an effective screening model, where identification of sexually active participants is efficient.

The response rates achieved in screening programmes will not only depend on the screening model used but will vary by the population targeted and the perseverance of those offering screening. Similar high response rates have been achieved using opportunistic screening in Holland $(90 \%)^{10}$; however, other populations in the United Kingdom have demonstrated lower rates $(45 \%)$ using this method in women. ${ }^{11}$ The efficacy of systematic screening using postal invitations has been investigated in several European countries with uptake of screening varying between $33 \%$ and $51 \% .{ }^{12-15}$

This pilot study achieved significant population coverage despite the fact that screening was intentionally constrained during certain periods. In Portsmouth, initial uptake was higher than expected so testing was limited to five specimens/ day in each general practice during October 1999 and also in FPCs for the first 3 months, while testing facilities were increased. A similar study by Santer et al of opportunistic screening in women attending at general practice reported effective screening rates of $30 \%$ in those attending for cervical screening and $23 \%$ for contraception. ${ }^{16}$ In Portsmouth, where screening was fully implemented in general practice from the start of the programme, the effective screening rate was higher at $46 \%$. However, the phased implementation of screening in general practice in Wirral makes it difficult to interpret population coverage at that site. Santer et al commented that a "structured incentive system" and a public and professional awareness campaign would be required to raise the effective screening rate significantly above the levels that they demonstrated. This pilot programme indicates that when these factors are in place, the ESR can be significantly increased. The high level of test acceptability indicates that potentially the ESR could be much increased if improvements were made to programme implementation, thereby offering screening to more people.

The small sample achieved in the in-depth qualitative study limits the extent to which the views expressed here can be said to be representative of the screened population. However, the range of views expressed does provide some important directives for the operation of a national programme of chlamydia screening. Participants found the urine test to be universally acceptable from the start of the study, and those offered screening felt able to refuse the offer. Survey respondents also indicated that if screening had been performed using a clinician taken swab then acceptability would be significantly reduced. Self taken as opposed to clinician taken vulval swabs could be a viable non-invasive alternative sampling method. One study indicated that although the acceptability of self taken vulval swabs for chlamydial infection was good (68\%), significantly more women stated they would have preferred a urine specimen rather than a self taken swab for future testing. ${ }^{17}$ An evaluation of different specimen types showed similar findings, where $41.5 \%$ of women preferred to give a urine sample rather than a self taken swab. ${ }^{18}$

The qualitative interviews indicated that some aspects of the programme were not satisfactory-namely, the role of GP receptionists in giving out test forms. While we do not have sufficient data to quantify the extent to which these concerns are representative of all those screened, similar concerns were raised in the survey of health professionals undertaking the programme. In future programmes, the opportunistic model could be refined to give potential participants more privacy in the initial offer of screening.

Support for more widespread screening has been widely voiced by clinicians, including those in primary care, for several years. There have been calls for greater access to nucleic acid amplification testing methodologies using noninvasive samples and the need to improve both public and 
professional awareness. ${ }^{19} 20$ This study provides clear evidence that an opportunistic model is acceptable for large scale screening, and it is likely that the recently proposed national screening programme will, at least initially, follow this model. ${ }^{21}$

\section{ACKNOWLEDGEMENTS}

We would like to thank all the health professionals who offered screening in their clinics and all who aided study administration for their enthusiasm and hard work. We are extremely grateful to Debbie Keane and Lindsay Shone for assistance in study implementation and patient management. We are grateful to local steering groups for their assistance: Graham Oughton, Kathy Primrose, Rachael Sharp, Joyce Dewhurst, Colin Walker (Portsmouth) and Harriet Gill, Rob Tabb, Katy Kidd, Pauline Lightfoot, Graham Spearing, Andrea Dodd, Julie Hotchkiss, Linda Johnston, and Sue Chesters (Wirral). We acknowledge the nursing staff in the GU clinics on both sites for their valuable contribution and hard work especially Andrea Dodd (nurse manager, GUM Wirral). We thank those who developed information systems for reporting and analysis, in particular Shelley Young (Threshold Computing Ltd), Christopher Wroath, and Nick Richardson (CSDC). We are grateful to Nazma Nezza (PHLS Statistics Unit) for preliminary analyses. Finally, we also thank Sally Wellsteed and Kay Ellis (Department of Health) and Muir Gray (National Screening Committee) for their input and support during the project.

Funding: Department of Health.

Competing interests: None declared.

\section{CONTRIBUTORS}

JMP participated in protocol development, coordinated data management, and was the lead writer; MC developed the protocol, critical revision of paper, and is the guarantor of the study in addition to $\mathrm{JH}$ (Wirral) and SR (Portsmouth); PAR participated in protocol development, undertook the statistical analysis of the uptake data (with assistance from JMP) and critical revision of paper; EP, NJ, and CC coordinated, implemented, conducted interviews, and analysed the qualitative study and paper preparation; JH and SR were lead local study coordinators and participated in protocol development, management, and implementation of the study; HM, GH, and GU participated protocol development and were responsible for laboratory aspects and service provision; HM and GH were responsible for local data management; LM and TG organised patient coordination and follow up; VH, JT, and AG participated in protocol development and were responsible for GUM patient management along with Mary Hernon (clinical research fellow) in GUM Wirral; all authors commented on the paper.

\section{Authors' affiliations}

J Pimenta, M Catchpole, PHLS Communicable Disease Surveillance Centre, 61 Colindale Avenue, London NW9 5EQ, UK

P A Rogers, PHLS Statistics Unit

E Perkins, Health and Community Care Research Unit, University of Liverpool, Thompson Yates Building, The Quadrangle, Brownlow Hill, Liverpool L69 3GB, UK

N Jackson, Conway Smith Rose, 60 Charlotte Street, London WIP 2AX, UK

C Carlisle, School of Nursing and Midwifery, The University of Glasgow, 59 Oakfield Avenue, Glasgow G12 8LW, UK

S Randall, Ella Gordon Unit, St Mary's Hospital, Milton Road, Portsmouth PO3 6AD, UK

J Hopwood, T Gleave, Chlamydia Pilot Office, Evidence-based Practice Unit, St Catherine's Hospital, Church Road, Birkenhead, Wirral,

L42 OLQ, UK
G Hewitt, G Underhill, Portsmouth Public Health Laboratory, St Mary's Hospital (East Wing), Milton Road, Portsmouth PO3 6AQ, UK H Mallinson, Liverpool Public Health Laboratory, University Hospital

Aintree, Lower Lane, Liverpool L9 7AL, UK

L McLean, Chlamydia Pilot Office, Ella Gordon Unit, St Mary's Hospital, Milton Road, Portsmouth PO3 6AD, UK

J Tobin, V Harindra, Department of GU Medicine, St Mary's Hospital, Milton Road, Portsmouth PO3 6AD, UK

A Ghosh, Department of GU Medicine, Arrowe Park Hospital, Upton, Wirral, CH49 5PE, UK

\section{REFERENCES}

1 PHLS, DHSS and PS and the Scottish ISD(D) 5 Collaborative Group. Sexually transmitted infections in the UK: new episodes seen at genitourinary medicine clinics, 1995 to 2000. London: Public Health Laboratory Service, 2001.

2 Herrmann B, Johnsson A, Mårdh P-A. A retrospective study of efforts to diagnose infections by Chlamydia trachomatis in a Swedish county. Sex Transm Dis 1991;18:233-7.

3 Addiss DG, Vaughn ML, Ludka D, et al. Decreased prevalence of Chlamydia trachomatis infection associated with a selective screening programme in family planning clinics in Wisconsin. Sex Transm Dis 1993;20:28-34

4 Chief Medical Officer's Expert Advisory Group. Main report of the CMO's expert advisory group on Chlamydia trachomatis. London: Department of Health, 1998.

5 Catchpole M, Gray M, Hopwood J, et al. Chlamydia trachomatis screening pilot: Project initiation document. London: Department of Health, 2000

6 Office for National Statistics. Population estimates mid-1999. London: England and Wales National Statistics, 2000.

7 Johnson AM, Mercer CH, Erens B, et al. Sexual behaviour in Britain: partnerships, practices, and HIV risk behaviours. Lancet 2001;358:1835-42.

8 Stata Corporation. Stata Statistical Software: Release 7.0. College Station Texas: Stata Corporation, 2001.

9 Strauss A, Corbin J. Basics of qualitative research. London: Sage Publications, 1990.

10 Van den Hoek JAR, Mulder-Folkers DKF, Coutinho RA, et al. Opportunistic screening for genital infections with Chlamydia trachomatis among the sexually active population of Amsterdam. I. Over $90 \%$ participation and almost $5 \%$ prevalence. Ned Tijdschr Geneeskd 1999; 143:688-72

11 Tobin C, Aggarwal R, Clarke J, et al. Chlamydia trachomatis: opportunistic screening in primary care. Br J Gen Pract 2001;51:565-6.

12 Ostergaard L, Anderson B, Olesen F, et al. Efficacy of home sampling for screening of Chlamydia trachomatis: randomised study. BM 1998;371:26-7.

13 Stephenson J, Carder C, Copas A, et al. Home screening for chlamydial genital infection: is it acceptable to young men and women? Sex Transm Infect 2000;76:25-7.

14 Anderson B, Olesen F, Møller JK, et al. Population-based strategies for outreach screening of urogenital Chlamydia trachomatis infections: a randomised, controlled trial. J Infect Dis 2002;185:252-8.

15 Van Valkengoed IGM, Morré SA, van den Brule AJC, et al. Low diagnostic accuracy of selective screening criteria for asymptomatic Chlamydia trachomatis infections in the general population. Sex Transm Infect 2000;76:375-80.

16 Santer M, Warner P, Sutherland S. Opportunistic screening for chlamydia infection in general practice: can we reach young women? J Med Screen 2000;7:175-6.

17 Macmillan S, McKenzie H, Flett G, et al. Feasibility of patient-collected vulval swabs for the diagnosis of Chlamydia trachomatis in a family planning clinic: a pilot study. Proceedings of IV Meeting for the European for Chlamydia Research. Saikku P, ed. Finland: Universitas Helsingiensis, 2000.

18 Carder C, Robinson AJ, Broughton C, et al. Evaluation of self-taken samples for the presence of genital Chlamydia trachomatis infection in women using the ligase chain reaction assay. Int J STD AIDS 1999;10:776-9.

19 Oakeshott P. Screening for cervical chlamydial infection in general practice. BrJ Gen Pract 1999;49:923-4

20 Hicks N, Dawes $M$, Fleminger $M$, et al. Chlamydia infection in general practice. BM 1999;318:790-2

21 Department of Health. http://www.doh.gov.uk/chlamydscreen.ht 